\begin{tabular}{|l|l|l}
\hline Received : Maret 2018 & Accepted : April 2018 & Published : April 2018 \\
\hline
\end{tabular}

\title{
Analisa Head Mayor Dan Minor Pompa Chiller dengan Bukaan Katup Instalasi Pompa Tunggal
}

\author{
Arief Muliawan $^{1 *}$, Ahmad Yani ${ }^{2}$ \\ ${ }^{\prime}$ Teknik Elektro, Sekolah Tinggi Teknologi Bontang \\ ${ }^{2}$ Teknik Mesin, Universitas Trunajaya Bontang \\ "Email: ariefstitek@gmail.com
}

\begin{abstract}
Centrifugal pump is one type of pump that is widely used in the fields of industry, agriculture and household. Centrifugal pumps can be found in Chiller pumps used in PT. X Bontang. Research and analysis of single chiller pumps has been conducted. This study aims to calculate the head losses mayor and head losses minor on the variation of the opening of the single pump installation valve. In chiller pump research which writer do, use variation of valve opening $100 \%, 75 \%, 50 \%, 25 \%$ and $10 \%$. From the test results in the largest debit field shown on $100 \%$ opening with $0.0053 \mathrm{~m}^{3} / \mathrm{s}$. From the calculation results for head losses major obtained $4.629 \mathrm{~m} 100 \%$ opening and $1.151 \mathrm{~m}$ openings $10 \%$. In the calculation of head losses minor obtained $9.7 \mathrm{~m}$ openings $100 \%$ and $2.1 \mathrm{~m}$ openings $10 \%$. From the data obtained that the greater the valve opening the greater the head losses mayor and head losses minor.
\end{abstract}

Keywords: chiller pump, head losses mayor, head losses minor

\begin{abstract}
Abstrak
Pompa sentrifugal merupakan salah satu jenis pompa yang banyak digunakan dalam bidang industri, pertanian dan rumah tangga. Pompa sentrifugal dapat dijumpai pada pompa Chiller yang dipakai di perusahaan PT.X Bontang. Telah dilakukan penelitian dan analisis terhadap pompa chiller yang dipasang tunggal. Penelitian ini bertujuan untuk menghitung head losses mayor dan head losses minor pada variasi bukaan katup instalasi pompa tunggal. Dalam penelitian pompa chiller yang penulis lakukan, menggunakan variasi bukaan katup 100\%, 75\%, 50\%, 25\%, dan 10\%. Dari hasil pengujian dilapangan debit terbesar ditunjukan pada bukaan $100 \%$ dengan $0,0053 \mathrm{~m}^{3} / \mathrm{s}$. Dari hasil perhitungan untuk head losses mayor diperoleh $4,629 \mathrm{~m}$ bukaan $100 \%$ dan $1,151 \mathrm{~m}$ bukaan $10 \%$. Perhitungan head losses minor diperoleh 9,7 m bukaan 100\% dan 2,1 m bukaan 10\%. Dari data yang diperoleh bahwa semakin besar bukaan katup maka semakin besar pula head losses mayor dan head losses minor.
\end{abstract}

Kata kunci: pompa chiller, head losses mayor, head losses minor

\section{Pendahuluan}

Pompa merupakan suatu alat untuk memindahkan air melalui distribusi pemipaan dimana terdapat perbedaan tekanan. Sehingga dibutuhkan pompa untuk membangkitkan perbedaan itu. Kebutuhan terhadap alat ini sangat besar karena fungsinya yang khusus dan spesifik yaitu dapat mengalirkan dan berperan sebagai pompa sirkulasi dalam suatu unit plant atau dapat juga diartikan sebagai alat untuk memindahkan fluida dari suatu unit operasi ke unit operasi selanjutnya. Telah banyak dilakukan pengujian pompa sebagai pembangkit listrik mikrohidro untuk menentukan daya hasil keluaran maupun pengujian sudu turbin [1], [2] dan [3].

Karakteristik pompa merupakan hubungan antara tinggi tekan (head), kapasitas, daya dan efisiensi. Hubungan tinggi tekan akan digambarkan pada akibat kerugian gesekan (head losses mayor) dan kerugian akibat jalur pemipaan (head losses 
minor) [4]. Dengan pemahaman akan akibat kerugian dalam penggunaan pompa dan pemipaan maka dapat membantu meminimalisir kehilangan energi pada sistem pemipaan yang dipergunakan [5]. Telah banyak dilakukan simulasi penggunaan karakteristik jalus distribusi air seperti yang dilakukan oleh Chanson [6].

Pompa yang ada di PT.X Bontang umumnya bersifat sentrifugal. Pompa tersebut dipakai .untuk mensirkulisasikan air di chiller dan untuk proses absorber unit. Jenis pompa chiller yang digunakan dalam sistem tersebut adalah jenis pompa sentrifugal dengan poros dipasang horizontal dengan kapasitas $0,0053 \mathrm{~m}^{3} / \mathrm{s}$. Dengan jumlah pompa sejenis yang terpasang sebanyak 3 buah yang terpasang secara seri dan paralel seperti yang ditunjukan pada Gambar 1.

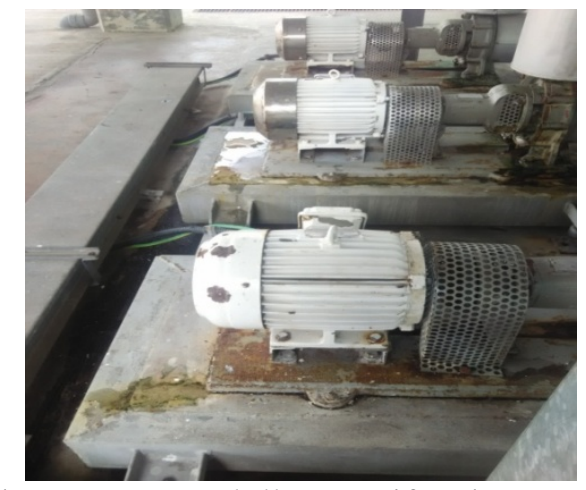

Gambar 1. Pompa chiller sentrifugal susunan seri

Pada penelitian ini akan diketahui kehilangan energi pada pompa chiller yang dipakai secara rinci sehingga dapat dijadikan suatu pertimbangan alternatif pemakaian dalam pembuatan instalasi pompa dengan karakteristik fluida yang sama. Penelitian ini akan mempergunakan pompa tunggal yang berfungsi untuk menaikan fluida dari bak penampungan ke pompa, selanjutnya dilakukan pengamatan pada flowmeter untuk melihat besarnya debit air. Penelitian kerugian aliran pada instalasi pompa bertujuan untuk menganalisis kerugian gesekan (head losses mayor) dan kerugian pemipaan (head losses minor) pada pemakaian pompa chiller yang dipasang tunggal.

\subsection{Kajian Literatur}

Kapasitas $(Q)$ biasanya dinyatakan dalam $\mathrm{m}^{3} / \mathrm{s}$. Fluida pada dasarnya berhubungan langsung antara kapasitas dalam pipa dan kecepatan aliran. Hubungan ini sebagaimana ditunjukkan dalam Pers. (1) [7].

$$
Q=\frac{V}{t} \quad \text { atau } \quad Q=v \times A
$$

Dimana, $Q$ adalah kapasitas aliran $\left(\mathrm{m}^{3} / \mathrm{s}\right), V$ adalah volume aliran $\left(\mathrm{m}^{3}\right), t$ adalah waktu aliran (s), $v$ adalah kecepatan aliran $(\mathrm{m} / \mathrm{s})$, dan $A$ adalah luas penampang $\left(\mathrm{m}^{2}\right)$.

Head pompa merupakan energi per satuan berat yang harus disediakan untuk mengalirkan sejumlah zat cair yang direncanakan sesuai dengan kondisi instalasi pompa, atau tekanan untuk mengalirkan sejumlah zat cair,yang umumnya dinyatakan dalam satuan panjang. Dalam persamaan Bernauli, ada tiga macam head (energi) fluida dari sistem instalasi aliran, yaitu, energi tekanan, energi kinetik dan energi potensial Hal ini dapat dinyatakan dengan Pers. (2).

$$
H_{t}=H_{d}+H_{s}+H_{f}+H_{m}
$$

Dimana $H_{p}$ adalah head statis pompa (m), $H_{d}$ adalah head discharge $(\mathrm{m}), H_{s}$ adalah head suction $(\mathrm{m}), \mathrm{H}_{\mathrm{f}}$ adalah head losses mayor $(\mathrm{m})$, dan $H_{m}$ adalah head losses minor (m).

Permukaan air berubah-ubah dengan perbedaan besar, head statis total harus ditentukan dengan mempertimbangkan karakteristik pompa, besarnya selisih perubahan permukaan air, dan dasar yang di pakai untuk menentukan jumlah air yang harus dipompa. Sehingga dalam penggunaan pompa chiller perlu diperhitungkan head Losses mayor dan minor.

Untuk menghitung kerugian gesek (head losses mayor) di dalam pipa dapat dipakai Pers. (3) [7].

$$
H_{f}=f \frac{L}{D} \cdot \frac{v^{2}}{2 g}
$$

Dimana $v$ adalah kecepatan rata-rata aliran di dalam pipa $(\mathrm{m} / \mathrm{s}), H_{f}$ adalah head kerugian gesek dalam pipa (m), $f$ adalah koefisien kerugian gesek, $g$ adalah percepatan grafitasi $\left(9,8 \mathrm{~m} / \mathrm{s}^{2}\right)$, dan $L$ adalah panjang pipa $(\mathrm{m})$.

Selanjutnya, untuk aliran yang laminar dan yang turbulen terdapat rumus yang berbeda. Sebagai patokan apakah suatu aliran itu laminer atau turbulen, dipakai bilangan Reynolds, seperti Pers. (4). 


$$
\operatorname{Re}=\frac{\rho \cdot v \cdot D}{\mu}
$$

Dimana $R_{e}$ adalah Reynold Number, $\rho$ adalah massa jenis cairan $\left(\mathrm{kg} / \mathrm{m}^{3}\right), v$ adalah kecepatan rata-rata aliran $(\mathrm{m} / \mathrm{s})$, dan $\mu$ adalah viscositas absolut cairan (kg/m.s). Pada $R e<2300$, aliran bersifat laminer. Pada $R e>4000$, aliran bersifat turbulen. Pada $R e=2300-4000$ terdapat daerah transisi, dimana aliran dapat bersifat laminer atau turbulen tergantung pada kondisi pipa atau aliran.

Dalam hal aliran laminer, koefisien kerugian gesek untuk pipa $(f)$ dinyatakan dalam Pers. (5).
$f=\frac{64}{R E}$

Untuk menghitung kerugian gesek pada pipa pada aliran turbulen terdapat berbagai rumus empiris. Untuk mencari koefisien gesek pipa $(f)$ dapat menggunakan diagram Moody seperti yang ditunjukkan pada Gambar 2. Untuk mengetahui kekasaran relative pipa dapat dicari dengan menggunakan Pers. (6).

Kekasaran relative $=\varepsilon / d$ Pers. (6)

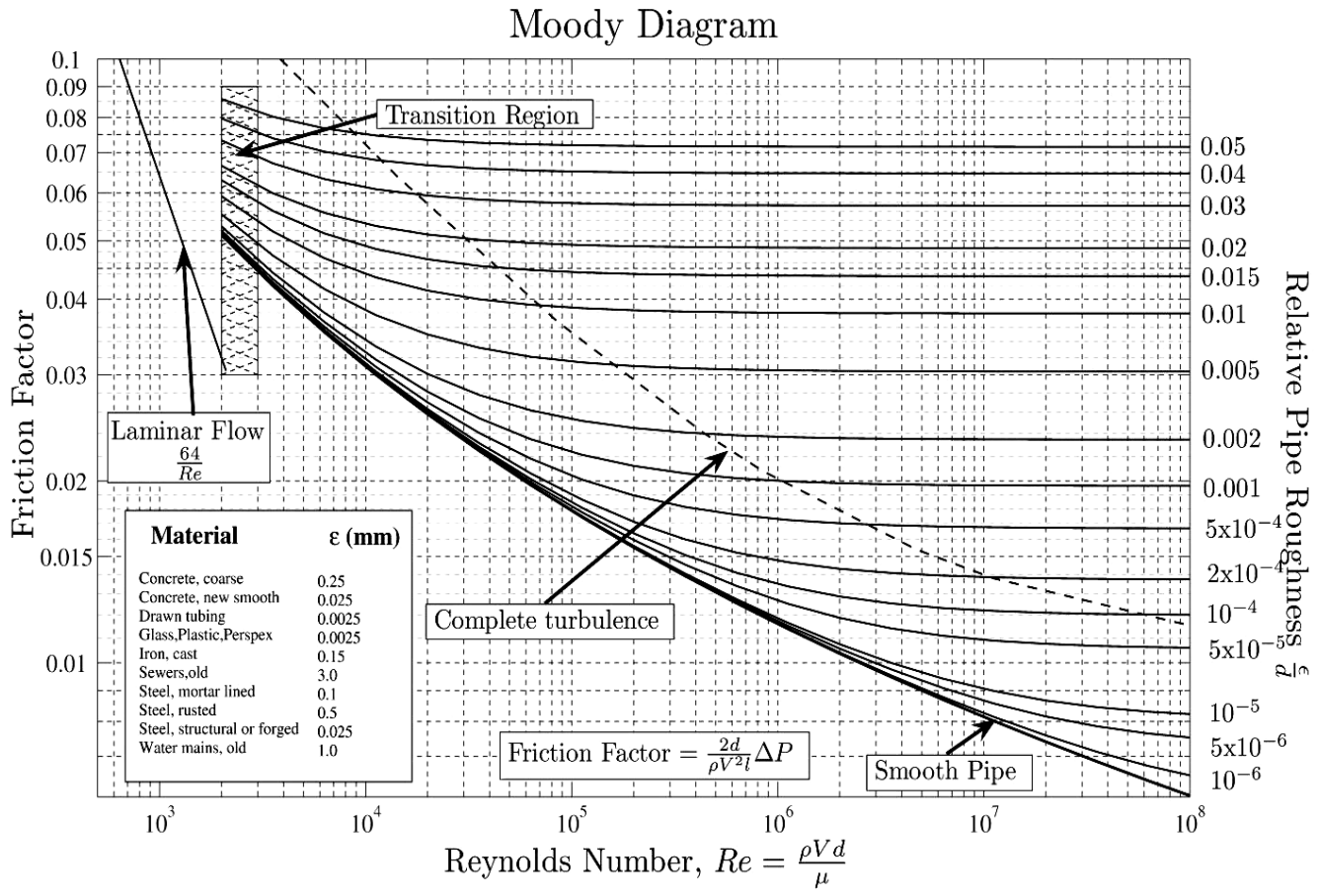

Gambar 2. Diagram Moody

Untuk menghitung kerugian dalam jalur pipa (head losses minor) di dalam aliran melalui jalur pipa, kerugian akan terjadi apabila ukuran pipa bentuk penampang, atau arah aliran berubah, kerugian head ditempat-tempat transisi yang dimiliki itu dapat dinyatakan secara umum dengan Pers. (7) [7].

$$
H_{f m}=n f \cdot k \cdot \frac{v^{2}}{2 g}
$$

Dimana $H_{f m}$ adalah head losses minor (m), $n f$ adalah jumlah fitting atau valve untuk diameter yang sama, $k$ adalah koefisien friksi, $v$ adalah kecepatan rata-rata aliran $(\mathrm{m} / \mathrm{s})$, dan $\mathrm{g}$ adalah percepatan gravitasi $\left(9,81 \mathrm{~m} / \mathrm{s}^{2}\right)$.

\section{Metoda Penelitian}

\subsection{Alat Dan Bahan} yakni:

Alat yang dipergunakan dalam penelitian ini
a. Meteran air
b. Valve
c. Elbow
d. Pressure gauge 
Dengan spesifikasi pompa chiller dengan jenis EBARA model FSA80X65 FS4JA sebagai berikut:

Kapasitas: 85 USGPM $=0,0053 \mathrm{~m}^{3} / \mathrm{s}$

Discharge pressure: 2.6 bar

Suction Pressure: -0.1 bar

Differensial Pressure: 2,7 bar

Head: $20 \mathrm{~m}$

Speed: $1500 \mathrm{rpm}$

Diameter impeller: $80 / 65 \mathrm{~mm}$

Density: $997,1 \mathrm{~kg} / \mathrm{m}^{3}$ pada suhu $25{ }^{\circ} \mathrm{C}$

Viscosity: $0.8 \mathrm{cp}=0,0008 \mathrm{Ns} / \mathrm{m}^{2}$

Liquid: chiller water

Panjang keseluruhan pipa: $128 \mathrm{~m}$

\subsection{Pengujian}

Panjang keseluruhan pipa dengan diameter $65 \mathrm{~mm}$ yang digunakan pada pengujian pompa tunggal adalah $128 \mathrm{~m}$. Prosedur pengujian dilakukan dengan mempertimbagkan karakteristik pompa chiller tunggal diantaranya:

a. Mengukur volume air, putaran poros pompa dan waktu.

b. Pengukuran dilakukan berulang dengan bukaan katup $100 \%, 75 \%, 50 \%, 25 \%$ dan $10 \%$.

c. Menyusun pompa sesuai Gambar 3 .

d. Menghitung kecepatan aliran, bilangan Reynold dan memprediksi koefisien gesek untuk perhitungan head losses mayor.

e. Menghitung koefisien pemipaan untuk perhitungan head losses minor.

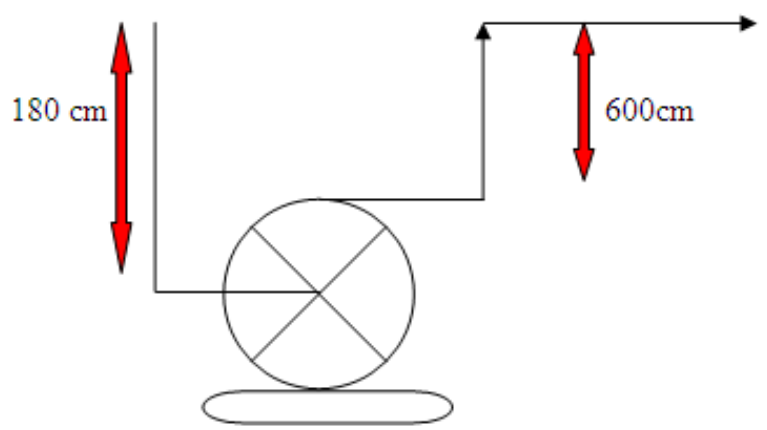

Gambar 3. Skema pompa tunggal

\section{Hasil Penelitian}

\subsection{Kapasitas Aktual Pompa}

Pengukuran dilakukan dengan mengukur volume air mengunakan water meter selama 60 detik disetiap bukaan katup. Variasi bukaan katup dilakukan pada bukaan katup 100\%, $75 \%, 50 \%$, $25 \%$ dan $10 \%$. Hasil pengukuran dapat dilihat pada Tabel 1. Dari hasil pengukuran dilapangan yang ditunjukan pada Tabel 1 pada bukaan valve dapat diperoleh kapasitas air dengan menggunakan Pers. (1). Dengan memanfaatkan Pers. (1) diperoleh kapasitas pompa untuk setiap bukaan dapat ditunjukan pada Tabel 2.

Tabel 1. Hasil pengukuran terhadap pompa chiller

\begin{tabular}{ccccc}
\hline $\begin{array}{c}\text { Peng- } \\
\text { ukuran }\end{array}$ & $\begin{array}{c}\text { Bukaa } \\
\mathrm{n} \\
\text { Katup } \\
(\%)\end{array}$ & $\begin{array}{c}\text { Volum } \\
\mathrm{e} \\
\left(\mathrm{m}^{3}\right)\end{array}$ & $\begin{array}{c}\text { Waktu } \\
(\mathrm{s})\end{array}$ & $\begin{array}{c}\text { Tekanan } \\
\left(\mathrm{kgf} / \mathrm{cm}^{2}\right. \\
)\end{array}$ \\
\hline I & 100 & 0.318 & 60 & 2,8 \\
\hline II & 75 & 0.310 & 60 & 3,1 \\
\hline III & 50 & 0.295 & 60 & 3,3 \\
\hline IV & 25 & 0.225 & 60 & 3,6 \\
\hline V & 10 & 0.15 & 60 & 4 \\
\hline
\end{tabular}

Tabel 2. Kapasitas air pompa chiller tunggal

Bukaan Katup Kapasitas air $\left(\mathrm{m}^{3} / \mathrm{s}\right)$

\begin{tabular}{cc}
$(\%)$ & \\
\hline 100 & 0.0053 \\
\hline 75 & 0.0051 \\
\hline 50 & 0.0040 \\
\hline 25 & 0.0037 \\
\hline 10 & 0.00225 \\
\hline
\end{tabular}

Dari hasil perhitungan diperoleh gambaran kapasitas air terhadap bukaan katup pada pompa chiller tunggal ditunjukan pada Gambar 4.

Dari Gambar 4 pengaruh bukaan katup terhadap kapasitas pompa dapat dilihat bahwa perubahan bukaan yang meningkat mengakibatkan debit keluaran semakin besar.

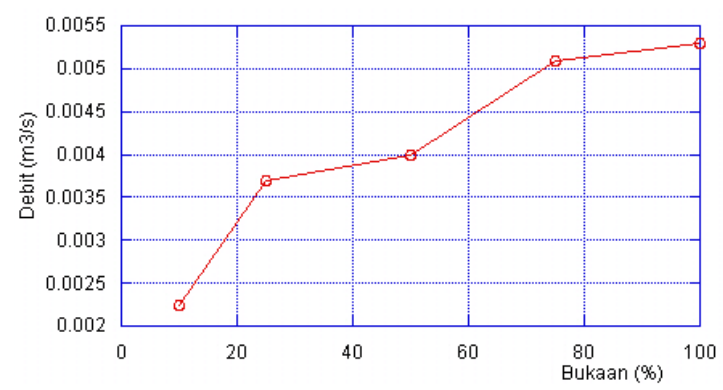

Gambar 4. Pengaruh bukaan katup terhadap kapasitas pompa

\subsection{Head Losses Mayor}

Untuk mencari head kerugian gesek (head losses mayor) pada instalasi pompa tunggal pipa diameter $65 \mathrm{~mm}$ bukaan katup 100\% menggunakan Pers. (3). Terlebih dahulu ditentukan 
besar kecepatan aliran dengan menggunakan Pers.

(1) sehingga:

$$
\begin{aligned}
v & =\frac{Q}{A}=\frac{0.0053}{\frac{\pi}{4} 0.065^{2}} \\
& =1.60 \mathrm{~m} / \mathrm{s}
\end{aligned}
$$

Maka didapatlah kecepatan aliran (v) pada bukaan katup $100 \%$ adalah sebesar $1,60 \mathrm{~m} / \mathrm{s}$. Untuk mencari faktor gesekan (f) pada pipa maka harus diketahui bilangan Reynold untuk mengetahui rumus empirik yang akan digunakan Pers. (4). Dari tabel sifat fisik air pada suhu $25^{\circ} \mathrm{C}$ didapat $\rho=997,1 \mathrm{~kg} / \mathrm{m}^{3}$ dan $\mu=0,0008 \mathrm{Ns} / \mathrm{m}^{2}$. Maka Bilangan Reynold $(R e)$ adalah:

$$
\begin{aligned}
& \operatorname{Re}=\frac{997,1 \mathrm{~kg} / \mathrm{m}^{3} .1,60 \mathrm{~m} / \mathrm{s} .0,065 \mathrm{~m}}{0.0008 N_{s} / \mathrm{m}^{2}} \\
& \operatorname{Re}=129623 \text { (Turbulen) }
\end{aligned}
$$

Untuk mengetahui kekasaran relative pipa dapat dicari dengan menggunakan Pers. (6). Dimana, untuk stainless steel adalah $0,015 \mathrm{~mm}=$ $0,000015 \mathrm{~m}$.

$$
\begin{aligned}
\text { Kekasaran relatif } & =\frac{0,000015}{0,065} \\
& =0,00023 \mathrm{~mm}
\end{aligned}
$$

Dari diagram Moody dapat dilihat bahwa koefisien gesek pada bilangan Reynold kisaran 120000 dan pada kekasaran relative 0,00023 adalah berkisar kurang lebih 0,018. Dengan diperolehnya nilai koefisien gesek maka dapat dihitung head kerugian gesek (head losses mayor) sebagai berikut:

$$
\begin{aligned}
H_{f} & =f \frac{L}{D} \cdot \frac{v^{2}}{2 g} \\
& =0.018 \frac{128}{0.065} \frac{1.60^{2}}{2(9.8)} \\
& =4.629 \mathrm{~m}
\end{aligned}
$$

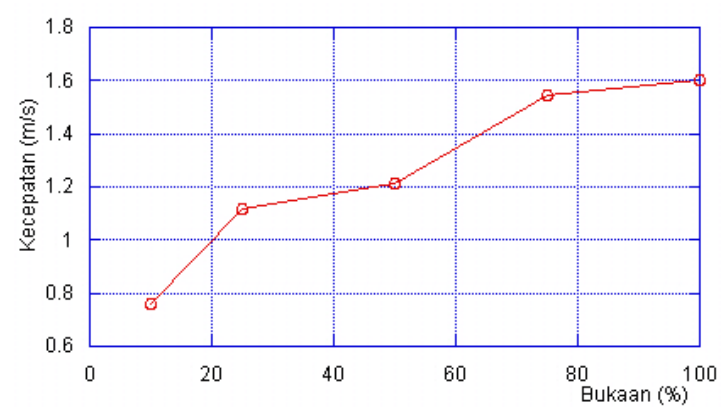

Gambar 5. Grafik pengaruh bukaan katup terhadap kecepatan air pompa tunggal

Maka head losses mayor untuk bukaan $100 \%$ ditunjukan dengan nilai 4,629 $\mathrm{m}$ sehingga untuk setiap bukaan katup dapat ditabulasikan yang dapat dilihat pada Tabel 3 dan ditunjukkan pada Gambar 5 pengaruh bukaan katup terhadap kecepatan pompa tunggal.

Gambar 5 menunjukan grafik pengaruh bukaan katup terhadap kecepatan air pada pompa tunggal. Dapat dilihat kecepatan air maksimum adalah $1,60 \mathrm{~m} / \mathrm{s}$ yakni pada bukaan katup $100 \%$ Selanjutnya untuk melihat pengaruh bukaan katup terhadap head losses mayor dapat dilihat pada Gambar 6.

Dari Gambar 6 dapat dilihat semakin besar bukaan katup maka head losses mayor semakin besar. Dimana pada bukaan katup 10\% head losses mayor adalah 1,151 m sedangkan head losses mayor pada bukaan katup $100 \%$ adalah sebesar $4,629 \mathrm{~m}$.

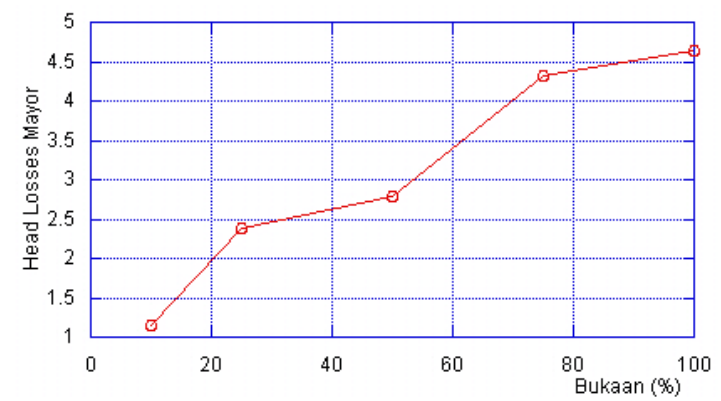

Gambar 6. Head losses mayor pada pompa tunggal 
Tabel 3. Head losses mayor untuk setiap bukaan pompa

\begin{tabular}{cccccc}
\hline $\begin{array}{c}\text { Bukaan } \\
\text { Katup } \\
(\%)\end{array}$ & $\begin{array}{c}\text { Debit } \\
\left(\mathrm{m}^{3} / \mathrm{s}\right)\end{array}$ & $\begin{array}{c}\text { Kecepatan } \\
(\mathrm{m} / \mathrm{s})\end{array}$ & $\begin{array}{c}\text { Bilangan } \\
\text { Reynold }\end{array}$ & $\begin{array}{c}\text { Koefisien } \\
\text { Gesek }\end{array}$ & $\begin{array}{c}\text { Head Losses } \\
\text { Mayor }(\mathrm{m})\end{array}$ \\
\hline 100 & 0,0053 & 1,60 & 129623 & 0,018 & 4,629 \\
\hline 75 & 0,0051 & 1,545 & 125167 & 0,018 & 4,316 \\
\hline 50 & 0,0040 & 1,21 & 98027 & 0,019 & 2,79 \\
\hline 25 & 0,0037 & 1,12 & 90834 & 0,020 & 2,394 \\
\hline 10 & 0,00225 & 0,757 & 61327 & 0,020 & 1,151 \\
\hline
\end{tabular}

\subsection{Head Losses Minor}

Pada instalasi pompa tunggal terdapat head kerugian dalam pipa (head losses minor). Untuk mencari perubahan yang terjadi terlebih dahulu ditentukan koefisien kerugian pipa tunggal ditunjukan pada Tabel 4.

Dari penjumlahan koefisien kerugian pada Tabel 4 maka jumlahnya pemipaan pipa $65 \mathrm{~mm}$ diperoleh $\sum K=74,3$. Dengan menggunakan Pers. (7) pada pipa $65 \mathrm{~mm}$ dengan bukaan katup $100 \%$ diperoleh:

$$
H_{f m}=74,3 \frac{1.60^{2}}{2 \cdot 9.8}=9,7 \mathrm{~m}
$$

Tabel 4. Koefisien pipa pompa tunggal

\begin{tabular}{lccc}
\hline Condition & $\mathrm{N}$ & $\mathrm{K}$ & $\mathrm{NK}$ \\
\hline Elbow $90^{\circ}$ & 25 & 1,5 & 37,5 \\
\hline Gate valve & 15 & 0,15 & 1,8 \\
\hline Gate valve, 3/4 closed & 1 & 17 & 17 \\
\hline Diagram valve open & 1 & 2,3 & 2,3 \\
\hline $\begin{array}{l}\text { Elbow, flange long } \\
\text { radius } 90^{\circ}\end{array}$ & 1 & 0,7 & 0,7 \\
\hline $\begin{array}{l}\text { Water meter } \\
\begin{array}{l}\text { Tee, threaded, dividing } \\
\text { branch flow }\end{array}\end{array}$ & 1 & 7 & 7 \\
\hline
\end{tabular}

Tabel 5. Head losses minor pompa tunggal

\begin{tabular}{cccc}
\hline $\begin{array}{c}\text { Bukaan } \\
\text { Katup } \\
(\%)\end{array}$ & $\begin{array}{c}\text { Debit } \\
\left(\mathrm{m}^{3} / \mathrm{s}\right)\end{array}$ & $\begin{array}{c}\text { Kecepatan } \\
(\mathrm{m} / \mathrm{s})\end{array}$ & $\begin{array}{c}\text { Head } \\
\text { Losses } \\
\text { Minor }(\mathrm{m})\end{array}$ \\
\hline 100 & 0,0053 & 1,60 & 9,7 \\
\hline 75 & 0,0051 & 1,545 & 9,0 \\
\hline 50 & 0,0040 & 1,21 & 5,6 \\
\hline 25 & 0,0037 & 1,12 & 4,7 \\
\hline 10 & 0,00225 & 0,757 & 2,1 \\
\hline
\end{tabular}

Dengan menggunakan Pers. (7) maka head losser minor untuk semua bukaan katup dapat ditabulasikan pada Tabel 5. Dari Tabel 5 dapat ditampilkan grafik untuk meninjau fenomena pengaruh bukaan katup terhadap head losses minor pada Gambar 7.

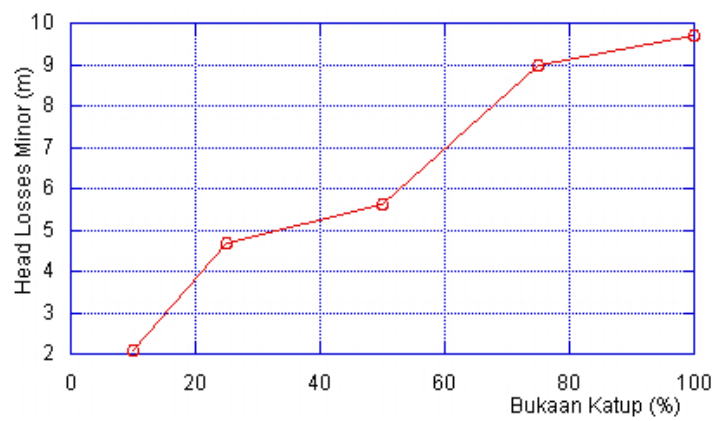

Gambar 7. Grafik pengaruh bukaan katup terhadap head losses minor pada pompa tunggal

Dapat dilihat bahwa semakin besar bukaan katup maka head losses minor semakin besar. Head losess minor maksimum yakni pada bukaan $100 \%$ adalah sebesar $9,7 \mathrm{~m}$.

\section{Kesimpulan}

Berdasarkan hasil pengujian yang telah dilakukan untuk variasi bukaan katup terhadap kapasitas air diperoleh semakin besar bukaan katup semakin besar pula debit yang dihasilkan. Dalam Perhitungan kerugian gesekan (head losses mayor) dan kerugian pemipaan (head losses minor), semakin besar bukaan katup maka semakin besar pula nilai head yang ditimbulkan akibat bukaan tersebut.

\section{Saran}

Diperlukan adanya penelitian lebih lanjut analisa head losses mayor dan head losses minor pada pompa chiller yang dibuat secara seri maupun secara paralel. 


\section{Daftar Pustaka}

[1] G. Suwoto, "Kaji Eksperimental Kinerja Turbin Air Hasil Modifikasi Pompa Sentrifugal Untuk Pembangkit Listrik Tenaga Mikrohidro," in Seminar SNTT ke3 Universitas Wahid Hasim Semarang, 2012, pp. 60-64

[2] Rosmiati and A. Yani, "Pengaruh Variasi Diameter Nosel Terhadap Torsi dan Daya Turbin Air," J. Turbo, vol. 6, no. 1, pp. 1421, 2017.

[3] A. Muliawan and A. Yani, "Analisis Daya Dan Efisiensi Turbin Air Kinetis Akibat Perubahan Putaran Runner," J. Sainstek, vol. 8, no. 1, pp. 1-9, 2016.

[4] F. M. Sitompul and M. Hazwi, "Pengujian Pengaruh Variasi Head Supply dan Panjang Langkah Katup Limbah Terhadap Unjuk Kerja Pompa Hidram," J Dinamis, vol.8, no. 4, pp. 224-230, 2014.

[5] Fuazen. "Pengaruh Variasi Diameter Pipa Hisap Pada Sistem Perpipaan Tunggal Terhadap Debit Pompa." J. Suara Teknik: vol 4, no.1, pp.1-7, 2017 .

[6] H. Chanson, "Introducing originality and innovation in engineering teaching: The hydraulic design of culverts," Eur. J. Eng. Educ., vol. 25, no. 4, pp. 377-391, 2000.

[7] V. L. Streeter and E. B Wylie, Mekanika Fluida jilid 1. Jakarta: Penerbit Erlangga, 1999. 